УДК 615.457

DOI 10.18413/2687-0940-2020-43-2-249-256

\title{
РАЗРАБОТКА МАЛОИНВАЗИВНОГО СПОСОБА ПОДГОТОВКИ КОСТНОЙ ТКАНИ ПЕРЕД ИМПЛАНТАЦИЕЙ С ИСПОЛЬЗОВАНИЕМ БИОЛОГИЧЕСКОГО ПОТЕНЦИАЛА СОБСТВЕННОГО ОРГАНИЗМА
}

\section{THE DEVELOP OF A MINIMALLY INVASIVE METHOD FOR PREPARING BONE TISSUE BEFORE IMPLANTATION USING BIOLOGICAL POTENTIAL OF BODY}

\author{
Н.М. Погосян ${ }^{1,4}$, М.С. Новожилова ${ }^{2}$, Р.С. Габов ${ }^{3}$, И.П. Рыжова ${ }^{4}$ \\ N.M. Pogosian ${ }^{1,4}$, M.S. Novozhilova ${ }^{2}$, R.S. Gabov ${ }^{3}$, I.P. Ryzhova ${ }^{4}$ \\ ${ }^{1}$ Стоматологическая клиника «Студия С», \\ Россия, 620010, г. Екатеринбург, ул. Орденоносцев, 8 \\ 2354 Окружной военный клинический госпиталь Министерства обороны РФ, \\ Россия, 620010, г. Екатеринбург, ул. Декабристов, 85 \\ ${ }^{3}$ Стоматологическая клиника «Приор М», \\ Россия, 620014, г. Екатеринбург, ул. Маршала Жукова, 14 \\ ${ }^{4}$ Белгородский государственный национальный исследовательский университет, \\ Россия, 308015, г. Белгород, ул. Победы, д. 85 \\ ${ }^{1}$ Dental Clinic «Studiya S», 8 St. Ordenonoscev, Ekaterinburg, 620010, Russia \\ 2354 District military clinical hospital, 85 St. Dekabristov, 620010, Russia \\ ${ }^{3}$ Dental Clinic «Prior M», 14 St. Marshal Zhukov, Ekaterinburg, 620014, Russia \\ ${ }^{4}$ Belgorod National Research University, 85 Pobedy St., Belgorod, 308015, Russia \\ Email:donatellka06@gmail.com
}

\begin{abstract}
Аннотация
В статье представлены результаты исследования разработанного способа подготовки костной ткани перед имплантацией. Восстановление отсутствующих зубов с применением имплантатов в последнее время расширило свои показания. В современной стоматологии уменьшилось число абсолютных противопоказаний для проведения имплантации. Перед планированием комплексной реабилитации пациента врач-стоматолог должен оценить положение соседних зубов, зубов антагонистов, биотип десны, ширину и высоту альвеолярного гребня в зоне вмешательства. При недостаточном объеме костной или мягкой ткани проводятся костнопластические операции. Наиболее широкую популярность приобрели методы восстановления костной ткани с применением аутокости и ксенографта. Но они имеют ряд недостатков, таких как труднодоступность донорских участков для забора костной ткани, несколько этапов хирургического вмешательства, риск осложнений в виде дезинтеграции костного материала или экспозиции используемой барьерной мембраны. Это приводит к финансовым затратам для пациентов и к увеличению сроков лечения. На базе стоматологической клиники «Студия С» г. Екатеринбурга был разработан способ подготовки костной ткани перед имплантацией. Данный способ включает в себя подготовку костной альвеолы перед имплантацией с использованием биологического потенциала собственных тканей. Преимуществами данного способа являются уменьшение сроков лечения, отсутствие повторных хирургических вмешательств и рубцовых изменений и достижение стабильного результата.
\end{abstract}

\footnotetext{
Abstract

The article presents result of studies developed method of bone regeneration before implantation. In modern dentistry indications for implantation have expanded. However, before planning implantation, the doctor needs to assess not only the position of adjacent teeth relative to the defect, but also the quantity and quality of bone tissue in the implantation zone. If there is insufficient volume of bone or soft tissue, we can use one of the methods of bone regenerations. Most have become very popular methods of bone regeneration with the use of autologous bone and xenograft. But they have a lot of disadvantages. The most common are the difficult
} 
access to donor sites for bone sampling, several stages of surgery, the risk of complications in the form of disintegration of bone material or exposure of the barrier membrane used. On the basis of the dental clinic «Studio S» from Ekaterinburg, a method of preparing bone tissue before implantation was developed. This method involves the preparation of the bone alveoli before implantation, using the biological potential of its own tissues. This method allows to reduce the time of treatment and financial costs of the patient, also the original volume of bone tissue is preserved and there are no scarring changes.

Ключевые слова: имплантация, костная пластика, малоинвазивность, каркасная мембрана. Keywords: implantation, guided tissue regeneration, minimally invasive, frame membrane.

\section{Введение}

В современной стоматологии с каждым годом увеличивается количество методов и материалов для восстановления недостающего объема костной ткани. Для успешной имплантации необходимо обеспечить достаточное количество костной ткани [Рыжова и др., 2018]. Расширить показания к использованию дентальных имплантатов в условиях атрофии костной ткани челюстей в местах их установки позволяет предварительное применение хирургических методов, направленных на увеличение объема костной ткани в челюстно-лицевой области, таких как аутокостная трансплантация, межкортикальная остеотомия и направленная костная регенерация с применением мембран [Иванов и др., 2011; Кулаков и др., 2015; Нерсесян и др., 2019]. Широко используемым методом восстановления недостающего объема костной ткани является метод направленной костной регенерации. Данная методика способствует лучшему восстановлению костной ткани в зоне постэкстракционной лунки и включает в себя использование каркасной и бескаркасной мембран в сочетании с остеопластическими материалами [Павленко, Shterenberg, 2015; De Rossi et al., 2015]. Особую популярность получила методика использования резорбируемой мембраны при предимплантационном моделировании и ремоделировании альвеолярного отростка после удаления зубов. По литературным данным, резорбируемая мембрана предоставляет возможность создать под ней пространство, соответствующее по топографии и размеру ремоделируемым тканям, а с другой - полноценно препятствует миграционной способности эпителия в зону регенерации [Гурин и др., 2013; Гударьян и др., 2014]. Она, как правило, достаточно эластична, хорошо заполняет имеющийся дефект, не требует дополнительного оперативного вмешательства с целью ее удаления, так как биоинтегрируется в окружающие ткани [Калмин и др., 2014]. Резорбируемые мембраны сами не определяют размер или форму будущего регенерата, а являются только барьером. Ее возможно зафиксировать к местным тканям, используя пины, или при помощи швов. Основным недостатком использования данного метода является неконтролируемая скорость резорбции, а также ее экспозиция с последующим присоединением воспалительного процесса. Ко всему прочему, мембраны с длительными - более 4-6 недель - сроками резорбции осумковываются и не подвергаются деградации [Мецуку и др., 2017; Кабаньков и др., 2019; Young-Kyun Kim et al., 2013].

Применение нерезорбируемой мембраны показано при необходимости получения большего объема костной ткани, преимущественно по высоте. Нерезорбируемая мембрана за счет своей жесткой структуры позволяет зафиксировать и удерживать восполняемый объем костного материала, что в дальнейшем дает прирост тканей до 5 мм. Недостатком данной методики является нарушение течения процессов регенерации при обнажении мембраны, и, что особо важно, необходимо повторное хирургическое вмешательство для удаления зафиксированной каркасной мембраны [Рыжова, Погосян, 2018; Prof. Dr. Ronald Yung, et al., 2017].

Большинство врачей, в основном после удаления зуба, образовавшийся дефект заполняют остеопластическим материалом или полученным фибрином, обогащенным тромбоцитами повышенной плотности - PRF сгусток [Шамардин, 2017; Трунин и др., 2018]. Любой материал, применяемый для профилактики или устранения дефектов костных или соединительных тканей, следует оценивать с учетом основных характеристик, к которым 
относятся биоактивность, биосовместимость, биорезистентность [Федорова и др., 2012]. Установлено, что тромбоциты играют важную роль в регуляции процессов регенерации поврежденных тканей, высвобождая факторы роста, которые запускают, и регулируют каскад процессов, направленных на миграцию, дифференциацию и пролиферацию клеток. Регуляция костно-пластических процессов происходит за счет костных морфогенетических белков, которые индуцируют дифференциацию костных клеток-предшественников в остеобласты. Соответственно, использование PRF в комбинации с остеопластическими материалами приводит к увеличению скорости образования костной ткани и улучшению ее качества [Просянникова и др., 2013; Климовицкий, Соловьев, 2015].

Учитывая все недостатки методик направленной костной регенерации и преимущества использования возможностей своего организма при выборе метода сохранения исходного объема костной ткани после удаления, была поставлена основная цель исследования.

Цель исследования - разработать щадящий, малоинвазивный способ сохранения объема исходной костной ткани после удаления зуба с использованием биологического потенциала организма. Провести анализ ее эффективности.

\section{Материалы и методы исследования}

Согласно поставленной цели, на базе стоматологической клиники «Студия С» г. Екатеринбурга были проведены исследования в группе пациентов, которые были направлены на предимплантационную подготовку. Были обследованы 42 человека, из них 23 женщины и 19 мужчин, возрастная группа от 25-50 лет. Пациенты отрицали наличие общесоматических заболеваний. Группы формировались по наличию таких нозологических заболеваний, как кариозные и некариозные поражения твердых тканей зубов, травмы коронковой части зубов, хронический апикальный периодонтит.

Исследуемые пациенты были разделены на 2 группы: контрольную и основную. Всем пациентам проводилась хирургическая подготовка полости рта, которая в контрольной группе заключалась в атравматичном удалении причинного зуба, восполнении лунки тромбоцитарной массой PRF, полученной методом центрифугирования вакуумной пробирки с активатором свертывания кремнезем, заполненной венозной кровью.

В основной группе проводилась хирургическая подготовка альвеолярной кости перед имплантацией с применением разработанного способа подготовки костной ткани альвеолы (патент № 2680797). Разработанный способ включает в себя следующие этапы: атравматичное удаление причинного зуба, выделение фрагмента удаленного зуба и его подготовка к реплантации. Фрагмент зуба выделяется фрезами, после чего проводится антисептическая обработка, пломбирование корневого канала материалом Proroot MTA. Acсистент врача-стоматолога, проводит взятие венозной крови в вакуумную пробирку с активатором свертываемости кремнезем для получения тромбоцитарной массы PRF методом центрифугирования. Лунка удаленного зуба заполняется полученной тромбоцитарной массой, позицируется выделенный фрагмент в лунку удаленного зуба на глубину 2 мм и накладываются швы рассасывающими материалами.

Проводилось динамическое наблюдение пациентов в обеих группах в два этапа, которые включали в себя, помимо стандартного клинического осмотра, анализ и изучение данных рентгенологических исследований и денситометрии. Первый этап исследования включал в себя клинические осмотры на 1, 3, 7 сутки после проведенного хирургического лечения и спустя 1 и 3 месяца.

Второй этап клинического обследования и динамического наблюдения проводится после установки имплантатов в подготовленную альвеолярную кость. Клинические осмотры проводились на 1, 3, 7 сутки после имплантации и спустя 1, 3 месяца.

На всех этапах проведенного лечения проводилось рентгенологическое исследование, включающее в себя ортопантомограмму, компьютерную томографию и внутриротовые прицельные снимки, а также денситометрическое измерение качества костной ткани 
по данным снимков компьютерной томографии. Результаты данного исследования были получены с применением конусно-лучевого томографа Planmeca ProMax 3D и аппарата Sirona Heliodent Plus. Для анализа результатов внутриротовых прицельных снимков использовалась программа DBSWin (компьютерное приложение программного обеспечения для хранения всех прицельных снимков). Анализ данных ортопантомограмм, 3D-изображений и денситометрическое измерение проводились с использованием программы программного обеспечения Windows Planmeca Romexis.

\section{Результаты клинических исследований их обсуждение}

Компьютерная томография проводилась пациентам исследуемых групп в два этапа. На первом этапе - до удаления зуба и спустя 3 месяца после проведенной хирургической подготовки. На втором этапе - спустя 3 месяца после проведенной имплантации.

В таблице 1 представлены результаты анализа рентгенологических данных, полученные методом компьютерной томографии у пациентов, проведенных до удаления зуба и после проведенной хирургической подготовки в обеих группах.

Таблица 1

Table 1

Результаты данных компьютерной томографии по количеству костной ткани в исследуемых группах до удаления и после хирургического вмешательства

The results of computed tomography data on the amount of bone tissue in the study groups before tooth extraction and after surgery

\begin{tabular}{|c|c|c|c|c|}
\hline \multirow{2}{*}{ № группы } & \multicolumn{2}{|c|}{$\begin{array}{c}\text { Исходный объем костной ткани до } \\
\text { удаления зуба }\end{array}$} & \multicolumn{2}{|c|}{ Объем костной ткани через 3 месяца } \\
\cline { 2 - 5 } & Ширина (мм) & Высота (мм) & Ширина (мм) & Высота (мм) \\
\hline 1 & $5,31 \pm 0,37$ & $6,03 \pm 0,40$ & $4,6 \pm 0,25$ & $5,6 \pm 0,33$ \\
\hline 2 & $5,52 \pm 0,42$ & $6,12 \pm 0,35$ & $6,15 \pm 0,41$ & $7,49 \pm 0,53$ \\
\hline
\end{tabular}

Примечание: Статистически значимые различия при $\mathrm{p} \leq 0,5$.

В таблице 2 представлены результаты данных проведенного денситометрического исследования при помощи анализа снимков компьютерной томографии. Единица измерения плотности костной ткани - Нu (Хаунсфилда).

Таблица 2

Table 2

Результаты данных денситометрии по качественному составу костной ткани в исследуемых группах до удаления зуба и после хирургической подготовки

The results of densitometry data and the qualitative composition of bone tissue in the study groups before tooth extraction and after surgical preparation

\begin{tabular}{|c|c|c|}
\hline \multirow{2}{*}{$№$ группы } & $\begin{array}{c}\text { Плотность костной ткани до удаления } \\
\text { зуба, Нu }\end{array}$ & $\begin{array}{c}\text { Плотность костной ткани через } \\
\text { 3 месяца, Нu }\end{array}$ \\
\hline 1 & $732 \pm 0,10$ & $668 \pm 0,02$ \\
\hline 2 & $626 \pm 0,01$ & $795 \pm 0,01$ \\
\hline
\end{tabular}

Примечание: Статистически значимые различия при $\mathrm{p} \leq 0,05$.

Проводя анализ полученных данных, можно сделать следующие выводы. В первой группе пациентов, которым было проведено атравматичное удаление зуба с последующим восполнением лунки удаленного зуба тромбоцитарной массой PRF, через 3 месяца после проведенной хирургической подготовки отмечается уменьшение высоты костной ткани на $\pm 0,43$ мм, это 7,13 \% от исходных данных. Также отмечается уменьшение ширины костной ткани на $\pm 0,71$ мм, что является меньше на 13,37 \% от первоначальной ширины. Дан- 
ные денситометрического исследования показали снижение плотности костной ткани на $\pm 64 \mathrm{Hu}$, это на $8.74 \%$ меньше первоначальных данных.

Во второй группе пациентов, которым была проведена хирургическая подготовка разработанным способом, были получены следующие данные. Увеличение высоты костной ткани на $\pm 1,37$ мм, что соответствует увеличению на 22,39 \% от исходных данных. Увеличение ширины костной ткани на $\pm 0,63$ мм, что соответствует увеличению костной ткани на $11,41 \%$. Данные денситометрии показали увеличение показателей качества костной ткани на $\pm 169 \mathrm{Hu}$, что соответствует 27 \% от исходных данных.

Второй этап исследования включал в себя анализ и сравнение данных рентгенологического и денситометрического исследования в обеих исследуемых группах перед имплантацией и спустя три месяца после проведенной имплантации.

В таблице 3 представлен сравнительный анализ данных компьютерной томографии у исследуемых групп после проведенной хирургической подготовки и спустя 3 месяца после имплантации.

Таблица 3

Table 3

Результаты данных компьютерной томографии по количеству костной ткани на втором этапе исследования

The results of computed tomography data on the amount of bone tissue in the second stage of the study

\begin{tabular}{|c|c|c|c|c|}
\hline \multirow{2}{*}{ № группы } & \multicolumn{2}{|c|}{$\begin{array}{c}\text { Объем костной ткани после } \\
\text { хирургической подготовки }\end{array}$} & $\begin{array}{c}\text { Объем костной ткани через 3 месяца } \\
\text { после имплантации }\end{array}$ \\
\cline { 2 - 5 } & Ширина (мм) & Высота (мм) & Ширина (мм) & Высота (мм) \\
\hline 1 & $4,6 \pm 0,25$ & $5,6 \pm 0,33$ & $4,23 \pm 0,61$ & $5,4 \pm 0,52$ \\
\hline 2 & $6,15 \pm 0,41$ & $7,49 \pm 0,5$ & $5,86 \pm 0,49$ & $7,49 \pm 0,32$ \\
\hline
\end{tabular}

Примечание: Статистически значимые различия при $\mathrm{p} \leq 0,5$.

В таблице 4 представлены результаты полученных данных после проведенного денситометрического исследования у исследуемых групп пациентов после проведенной хирургической подготовки и спустя 3 месяца после имплантации.

Таблица 4

Table 4

Результаты данных денситометрии по качественному составу костной ткани на втором этапе исследования

The results of densitometry data on the qualitative composition of bone tissue at the second stage of the study

\begin{tabular}{|c|c|c|}
\hline № группы & $\begin{array}{c}\text { Плотность костной ткани после } \\
\text { хирургической подготовки } \\
\text { Нu (Хаунсфилд) }\end{array}$ & $\begin{array}{c}\text { Плотность костной ткани через } \\
\text { 3 месяца после имплантации } \\
\text { Нu (Хаунсфилд) }\end{array}$ \\
\hline 1 & $732 \pm 0,2$ & $620 \pm 0,15$ \\
\hline 2 & $626 \pm 0.1$ & $728 \pm 0.103$ \\
\hline
\end{tabular}

Примечание: Статистически значимые различия при $\mathrm{p} \leq 0,5$.

В результате анализа полученных данных на втором этапе исследования были получены следующие данные. У контрольной группы пациентов отмечается уменьшение ширины и высоты альвеолярной кости от исходных данных на $\pm 0,37$ мм и $\pm 0,2$ мм, что соответствует уменьшению объема костной ткани по ширине на 8,04 \% и высоте 3,57 \%. Плотность костной ткани уменьшилась на $\pm 112 \mathrm{Hu}(15,3 \%)$.

В основной группе также отмечено уменьшение ширины альвеолярного гребня на $\pm 0,29$ мм, что соответствует уменьшению объема костной ткани по ширине на 4,72 \%. Плотность костной ткани увеличилась на $\pm 102 \mathrm{Hu}$, что соответствует увеличению на $16.29 \%$. 


\section{Заключение}

В результате проведенного исследования и анализа полученных данных, полученных путем изучения и сравнения результатов компьютерной томографии и денситометрических измерений, у исследуемых групп были сделаны следующие выводы. Разработанный способ подготовки альвеолярной кости лунки удаленного зуба перед имплантацией помогает не только сохранить исходные параметры костной ткани, но и увеличить объем костной ткани по ширине на 22,39 \% и 11,41 \% по высоте. Также разработанный способ улучшает качество костной ткани на $27 \%$. Данные значения сохраняются спустя 3 месяца после проведенной имплантации. Исходя из вышеперечисленного, можно сделать вывод, что разработанный способ имеет преимущества перед традиционным методом подготовки костной ткани. Помимо отсутствия нескольких этапов хирургического вмешательств, отсутствия рисков осложнений и травматичности вмешательства, у пациентов отмечается стабильность достигнутого результата, что всегда имеет положительное клиническое значение.

\section{Список литературы}

1. Гударьян А.А., Идашкина Н.Г., Ширинкин С.В. 2014. Сравнительная эффективность использования резорбируемых мембран из полимолочной кислоты и коллагена при регенерации костной ткани у больных периимплантитом. Медичні перспективи. 19 (1): 91-96.

2. Гурин А.Н, Федотов А.Ю., Деев Р.В., Комлев В.С. 2013. Направленная регенерация костной ткани с использованием барьерной мембраны на основе альгината натрия и октакальциевого фосфата. Журнал Клеточная трансплантология и тканевая инженерия. 8 (4): 70.

3. Климовицкий В.Г., Соловьев И.А. 2015. Применение плазмы, обогащенной тромбоцитами, в лечении повреждений мягких и костных тканей (обзор литературы). Журнал Травма. 16 (6): 77-80.

4. Кулаков А.А., Надточий А.Г., Брайловская Т.В., Бедретдинов Р.М., Магомедов Р.Н. 2015. Оценка состояния альвеолярной кости вокруг дентальных имплантатов, установленных после выполнения костнопластических операций, по данным рентгенологического анализа. Медицинский альманах. 3 (38): 178.

5. Мецуку И., Мураев А.А., Гажва Ю.В., Ивашкевич С.Г. 2017. Сравнительная характеристика различного типа барьерных мембран, используемых для направленной костной регенерации в стоматологии и челюстно-лицевой хирургии. Российский стоматологический журнал. 21 (5): 291.

6. Нерсесян П.М., Жолудев С.Е., Получшина Л.Г., Максимова А.Ю., Базарный В.В. 2019. Лабораторное обоснование атравматичности использования индивидуального формирователя десны при дентальной имплантации. Уральский медицинский журнал. 9 (177): 37.

7. Иванов С.Ю., Зайцев А.Б., Ямуркова Н.Ф., Мигура С.А., Губова В.М., Янцен И.Е., Акулов М.М., Мураев А.А. 2011. Исследование барьерной функции коллагеновой мембраны «Остеопласт» при заживлении костных дефектов в эксперименте. Современные технологии в медицине. 3: 35-38.

8. Кабаньков А.В., Иванов А.С., Мнацаканов С.С., Румакин В.П., Резниченко А.С. 2019. Особенности направленной регенерации костной ткани при использовании резорбируемых мембран на основе поливинилового спирта с добавлением фуллеренов. Вестник Витебского государственного университета. 18 (14): 91-97.

9. Калмин О.В., Никишин Д.В., Володина Ю.М. 2014. Морфологический анализ эффективности применения резорбируемой мембраны «Bio gide». Известия высших учебных заведений. Поволжский регион. Медицинские науки. 3 (31): 5-18.

10. Павленко A.B., Dr. Shterenberg. 2015. Синтетические остеотропные материалы для замещения костных дефектов в стоматологической практике. Журнал Дентальная имплантология и хирургия. С. 15.

11. Просянникова Н.В., Липова Е.В., Покровский К.А., Тарасенко Г.Н. 2013. Тромбоцитарная масса при хронических язвенных дефектах кожи. Российский журнал кожных и венерических болезней. 2: 20.

12. Рыжова И.П., Погосян Н.М. 2018. Современные подходы к восстановлению костной ткани при различных видах атрофии костной ткани челюстей. Сборник научных работ 46-й Международной научной конференции Евразийского Научного Объединения. С. 177-179. 
13. Рыжова И.П., Гонтарев С.Н., Ефимова А.С., Погосян Н.М. 2018. Оптимизация реплантации зуба с целью сохранения костной ткани альвеолы. Стоматология славянских государств. С. 249.

14. Трунин Д.А, Тлустенко В.П., Садыков М.И., Нестеров А.М., Постников М.А., Тугушев Р.И. 2018. Рентгенологический контроль регенерации лунки удаленного зуба (экспериментальное исследование). Известия Самарского научного центра российской академии наук. 20 (2): 154.

15. Федорова М.З., Надеждин С.В., Посохова В.Ф., Чуев В.В., Шатерникова В.А. 2012. Оценка биоактвиности и биосовместимости остеопластического материала в опытах in vitro и in vivo. Научные ведомости Белгородского государственного университета. 10-3 (129): 124-129.

16. Шамардин В.В. 2017. Опыт применения A-Prf и I-Prf в повседневной практике врача стоматолога на хирургическом амбулаторном приеме. Главный врач юга России. 2-1 (55): 27.

17. De Rossi V., Clementini M., Vittorini G., Mannocci A., De Sanctis M. 2015. Alveolar ridge preservation techniques: a systematic review and meta-analysis of histological and histomorphometrical data. Clinical. Oral. research. 26 (1): 50-68.

18. Prof. Dr. Ronald Yung, Dr. Stefan Neumayer, Dr. Jose Carlos Martins da Rosa. 2017. Innovations for alveolar ridge preservation - clinical strategies outside the box. The International Journal of Esthetic Dentistry. 12 (2): 5.

19. Young-Kyun Kim, Jeong Keun Lee, Kyung-Wook Kim, In-Woong Um and Masaru Murata (March 27th 2013). Healing Mechanism and Clinical Application of Autogenous Tooth Bone Graft Material, Advances in Biomaterials Science and Biomedical Applications, Rosario Pignatello, Intech Open, DOI: 10.5772/53200. Available from: https://www.intechopen.com/books/advances-in-biomaterialsscience-and-biomedical-applications/healing-mechanism-and-clinical-application-of-autogenous-toothbone-graft-material.

\section{References}

1. Gudar'jan A.A., Idashkina N.G., Shirinkin S.V. 2014. Sravnitel'naja jeffektivnost' ispol'zovanija rezorbiruemyh membran iz polimolochnoj kisloty i kollagena pri regeneracii kostnoj tkani u bol'nyh periimplantitom [Comparative efficiency of the use of resorbable membranes made of polylactic acid and collagen for bone regeneration in patients with peri-implantitis]. Medichni perspektivi. 19 (1): 91-96.

2. Gurin A.N., Fedotov A.Ju., Deev R.V., Komlev V.S. 2013. Napravlennaja regeneracija kostnoj tkani s ispol'zovaniem bar'ernoj membrany na osnove al'ginata natrija i oktakal'cievogo fosfata [Sodium alginate bioresorbable membrane and octacalcium phosphate biomaterial for guided bone regeneration]. Zhurnal Kletochnaja transplantologija i tkanevaja inzhenerija. 8 (4): 70.

3. Klimovickij V.G., Solov'ev I.A. 2015. Primenenie plazmy, obogashhennoj trombocitami, v lechenii povrezhdenij mjagkih i kostnyh tkanej (obzor literatury) [The use of platelet-rich plasma in the treatment of soft and bone tissue injuries (literature review)]. Zhurnal Travma. 16 (6): 77-80.

4. Kulakov A.A, Nadtochij A.G., Brajlovskaja T.V., Bedretdinov R.M., Magomedov R.N. 2015. Ocenka sostojanija al'veoljarnoj kosti vokrug dental'nyh implantatov, ustanovlennyh posle vypolnenija kostnoplasticheskih operacij, po dannym rentgenologicheskogo analiza [Evaluation of alveolar bone condition around dental implants set after carrying out of osteoplastics surgeries in accordance with the data of X-ray analysis]. Medicinskij al'manah. 3 (38): 178.

5. Mecuku I., Muraev A.A, Gazhva Ju.V., Ivashkevich S.G. 2017. Sravnitel'naja harakteristika razlichnogo tipa bar'ernyh membran,ispol'zuemyh dlja napravlennoj kostnoj regeneracii v stomatologii i cheljustno-licevoj hirurgii [Comporative characteristics of various types of membranes used for bone grafting and guided tissue regeneration in dentistry and maxillofacial surgery]. Rossijskij stomatologicheskij zhurnal. 21 (5): 291.

6. Nersesjan P.M., Zholudev S.E., Poluchshina L.G., Maksimova A.Ju., Bazarnyj V.V. 2019. Laboratornoe obosnovanie atravmatichnosti ispol'zovanija individual'nogo formirovatelja desny pri dental'noj implantacii [Laboratory substantiation of absence of trauma the use of individual abutments in dental implants]. Ural'skij medicinskij zhurnal. 9 (177): 37

7. Ivanov S.Ju., Zajcev A.B., Jamurkova N.F., Migura S.A., Gubova V.M., Jancen I.E., Akulov M.M., Muraev A.A. 2011. Issledovanie bar'ernoj funkcii kollagenovoj membrany «Osteoplast» pri zazhivlenii kostnyh defektov v jeksperimente [The study of barrier function of collagen membrane «Osteoplast» in healing bone defects in an experiments]. Sovremennye tehnologii v medicine. 3: 35-38.

8. Kaban'kov A.V., Ivanov A.S., Mnacakanov S.S., Rumakin V.P., Reznichenko A.S. 2019. Osobennosti napravlennoj regeneracii kostnoj tkani pri ispol'zovanii rezorbiruemyh membran na osnove polivinilovogo spirta s dobavleniem fullerenov [The peculiarities of the guided bone tissue regeneration 
on using resorbable membranes based on polyvinyl alcohol with the addition of c60 fullerenes ]. Vestnik Vitebskogo gosudarstvennogo universiteta. 18 (14): 91-97.

9. Kalmin O.V., Nikishin D.V., Volodina Ju.M. 2014. Morfologicheskij analiz jeffektivnosti primenenija rezorbiruemoj membrany «Bio gide» [Morfological analysis of effectiveness of a «Bio gide» resorbable membran]. Izvestija vysshih uchebnyh zavedenij. Povolzhskij region. Medicinskie nauki. 3 (31): 5-18.

10. Pavlenko A.V., Dr. Shterenberg. 2015. Sinteticheskie osteotropnye materialy dlja zameshhenija kostnyh defektov v stomatologicheskoj praktike [Synthetic osteotropic materials for replacement of bone defects in dental practice]. Dental'naja implantologija i hirurgija. S. 15.

11. Prosjannikova N.V., Lipova E.V., Pokrovskij K.A., Tarasenko G.N. 2013. Trombocitarnaja massa pri hronicheskih jazvennyh defektah kozhi [Platelet-rich plasma in the treatment of chronic skin ulcers]. Rossijskij zhurnal kozhnyh i venericheskih boleznej. 2: 20.

12. Ryzhova I.P., Pogosjan N.M. 2018. Sovremennye podhody k vosstanovleniju kostnoj tkani pri razlichnyh vidah atrofii kostnoj tkani cheljustej [Modern approaches to the restoration of bone tissue in various types of bone atrophy of the jaws]. Sbornik nauchnyh rabot 46-j Mezhdunarodnoj nauchnoj konferencii Evrazijskogo Nauchnogo Obedinenija. S. 177-179.

13. Ryzhova I.P., Gontarev S.N., Efimova A.S., Pogosjan N.M. 2018. Optimizacija replantacii zuba s cel'ju sohranenija kostnoj tkani al'veoly [Optimization of tooth replantation in order to preserve the bone tissue of the alveoli]. Stomatologija slavjanskih gosudarstv. S. 249.

14. Trunin D.A, Tlustenko V.P., Sadykov M.I., Nesterov A.M., Postnikov M.A., Tugushev R.I. 2018. Rentgenologicheskij kontrol' regeneracii lunki udalennogo zuba (experimental'noe issledovanie) [X-Ray monitoring of lunatic regeneration remove tooth (experimental study)]. Izvestija Samarskogo nauchnogo centra rossijskoj akademii nauk. 20 (2): 154.

15. Fedorova M.Z., Nadezhdin S.V., Posohova V.F., Chuev V.V., Shaternikova V.A. 2012. Ocenka bioaktvinosti i biosovmestimosti osteoplasticheskogo materiala $\mathrm{v}$ opytah in vitro i in vivo [Evaluation of bioactivity and biocompatibility of osteoplastic material in in vitro and in vivo]. Nauchnye vedomosti Belgorodskogo gosudarstvennogo universiteta. 10-3 (129): 124-129.

16. Shamardin V.V. 2017. Opyt primenenija A-Prf i I-Prf v povsednevnoj praktike vracha stomatologa na hirurgicheskom ambulatornom prieme [A-Prf and I-Prf experience in dentist daily practiceat outpatient surgery]. Glavnyj vrach juga Rossii. 2-1 (55): 27.

17. De Rossi V., Clementini M., Vittorini G., Mannocci A., De Sanctis M. 2015. Alveolar ridge preservation techniques: a systematic review and meta-analysis of histological and histomorphometrical data. Clinical. Oral. research. 26 (1): 50-68.

18. Prof. Dr. Ronald Yung, Dr. Stefan Neumayer, Dr. Jose Carlos Martins da Rosa. 2017. Innovations for alveolar ridge preservation - clinical strategies outside the box. The International Journal of Esthetic Dentistry. 12 (2): 5.

19. Young-Kyun Kim, Jeong Keun Lee, Kyung-Wook Kim, In-Woong Um and Masaru Murata (March 27th 2013). Healing Mechanism and Clinical Application of Autogenous Tooth Bone Graft Material, Advances in Biomaterials Science and Biomedical Applications, Rosario Pignatello, Intech Open, DOI: 10.5772/53200. Available from: https://www.intechopen.com/books/advances-in-biomaterialsscience-and-biomedical-applications/healing-mechanism-and-clinical-application-of-autogenous-toothbone-graft-material.

\section{Ссылка для цитирования статьи Link for article citation}

Погосян Н.М., Новожилова М.С., Габов Р.С., Рыжова И.П. 2019. Разработка малоинвазивного способа подготовки костной ткани перед имплантацией с использованием биологического потенциала собственного организма. Актуальные проблемы медицины, 43 (2): 249-256. DOI 10.18413/2687-0940-2020-43-2-249-256.

Pogosian N.M., Novozhilova M.S., Gabov R.S., Ryzhova I.P. 2019. The develop of a minimally invasive method for preparing bone tissue before implantation using biological potential of body. Challenges in Modern Medicine, 43 (2): 249-256 (in Russian). DOI 10.18413/2687-0940-2020-43-2-249-256. 